\title{
Seleção de progênies de meios-irmãos do composto Isanão VF-1 de milho na safra e safrinha
}

\author{
Selection of half sib progenies of Isanão VF-1 composite of maize in normal and late season crops
}

\author{
Liliam Silvia Candido ${ }^{\text {* }}$ João Antonio da Costa Andrade ${ }^{\text {II }}$ Fabiana Queiroz Garcia ${ }^{\text {II }}$ \\ Leandro Simões Azeredo Gonçalves ${ }^{I}$ Antonio Teixeira do Amaral Júnior ${ }^{I}$
}

RESUMO

O aumento significativo da produção de milho na segunda safra no Brasil, principalmente no centro-sul do país, têm estimulado os programas de melhoramento da cultura a selecionar genótipos que sejam adaptáveis às condições climáticas das diferentes épocas de semeadura. Nesse sentido, o objetivo do presente trabalho foi quantificar a interação progênies $x$ épocas de semeadura e verificar seus reflexos no progresso genético com o uso de índice de seleção multivariado para seleção de progênies do Composto Isanão VF-1 de milho. As semeaduras foram realizadas na segunda safra em 2004 e na primeira safra do ano agrícola 2004/05. Foram utilizadas 71 progênies de meios irmãos avaliadas em blocos ao acaso, com três repetições. Os caracteres avaliados foram: altura de plantas, altura de espigas, tombamento, prolificidade $e$ rendimento de grãos. Realizaram-se a decomposição da interação progênies $x$ épocas e foram estimados os ganhos pelo índice de seleção descrito por Mulamba e Mock. Houve predomínio da interação do tipo simples para maioria dos caracteres, exceto para prolificidade, que revelou $86 \%$ de interação do tipo complexa. Pelo índice de Mulamba e Mock, os ganhos proporcionais mais adequados para o conjunto de caracteres avaliados foi obtido pelos pesos econômicos atribuídos por tentativas. Os ganhos preditos foram de 1,41, 0,86, -13,03, 9,54 e 16,12\% para altura de planta, altura de espiga, tombamento, prolificidade e rendimento de grãos, respectivamente.

Palavras-chave: Zea mays L., parâmetros genéticos, interação genótipo $x$ ambiente, índice de seleção, ganho genético.

\section{ABSTRACT}

The significant increase in maize production in the second season crop in Brazil, mainly in central-south of the country have stimulated breeding programs to select genotypes adapted to the climatic conditions of different sowing times. The objective of this study was to quantify the progenies $x$ sowing times interaction and check its reflexes on the genetic progress with the use of multivariate selection for selection progenies of the maize Composite Isanão VF-1. Sowings were done in the second growing season, in 2004 and in first growing season of the 2004/05 crop year. A total of 71 half-sib progenies were evaluated in a randomized block design with three replications. The traits evaluated were: plant height, ear height, lodged and broken plants, prolificacy and grain yield. There was decomposition of progenies $x$ sowing times interaction and gains from selection index Mulamba and Mock were estimated. There was a predominance of the simple interaction for most traits, except prolificacy, which revealed $86 \%$ of complex type interaction. For the index Mulamba and Mock, proportional gains most appropriate for the traits set was obtained by the economic weights assigned by attempts. The predicted gains were 1.41, 0.86, -13.03, 9.54 and $16.12 \%$ for plant height, ear height, lodged and broken plants, prolificacy and grain yield, respectively.

Key words: Zea mays L., genetics parameters, genotype $x$ environment interaction, selection index, genetic gain.

\section{INTRODUÇÃO}

A cultura do milho é reconhecida como uma das principais responsáveis pela expansão da atividade agrícola brasileira. Seu cultivo é altamente beneficiado pela tecnologia e pelas inovações da pesquisa agrícola (AGUIAR et al., 2008). No Brasil, tem sido semeado em

IUniversidade Estadual do Norte Fluminense Darcy Ribeiro (UENF), 28013-602, Campos dos Goytacazes, RJ, Brasil. Email: bioliliam@yahoo.com.br. *Autor para correspondência.

IIUniversidade Estadual Paulista (UNESP), Faculdade de Engenharia de Ilha Solteira, Ilha Solteira, SP, Brasil. 
duas épocas, $1^{\underline{a}}$ safra ou época normal (setembro a novembro) e $2^{\text {a }}$ safra ou safrinha (janeiro a março, dependendo da região). A produção obtida na safrinha tem aumentado significativamente, principalmente no centro-sul do país, atestando a importancia da 2ª safra, que, em determinadas regiões, deixou de ser opção de inverno para se tornar cultura rentável.

Devido às diferenças climáticas existentes entre as épocas de safra e safrinha, é importante que os programas de melhoramento genético de milho avaliem a existência e magnitude da interação genótipos $\mathrm{x}$ ambientes. Dessa forma, é possível indicar a necessidade ou não da condução de programas específicos para cada época.

A interação genótipos $\mathrm{x}$ ambientes ocorre quando há respostas diferenciadas dos genótipos avaliados em diferentes ambientes. Segundo CRUZ et al. (2004), a interação genótipo x ambiente está associada a dois fatores. O primeiro, denominado simples, é proporcionado pela diferença entre genótipos. O segundo, denominado complexo, é dado pela ausência de correlação entre os genótipos. Assim, a correlação baixa indica que o genótipo superior em um ambiente, normalmente, não terá o mesmo desempenho em outro ambiente (CARGNIN et al., 2006).

A interação genótipos $\mathrm{x}$ ambientes não interfere apenas na recomendação de cultivares, mas também dificulta o trabalho do melhorista, que necessita adotar critérios diferenciados para selecionar genótipos superiores e usar métodos alternativos da identificação de material de alto potencial genético (CRUZ et al., 2004), principalmente quando se trata de interação complexa.

Nesse sentido, o objetivo do presente trabalho foi quantificar a interação progênies x épocas de semeadura e verificar seus reflexos no progresso genético com o uso de índice de seleção multivariado para seleção de progênies do Composto Isanão VF-1 de milho.

\section{MATERIAL E MÉTODOS}

O composto Isanão VF-1 foi obtido a partir do Composto Flintisa de milho que possui altura normal. Maiores detalhes sobre a formação do composto podem ser encontrados em GARCIA (2005) e CANDIDO \&ANDRADE (2008).

Os experimentos foram conduzidos em duas épocas de semeadura (safra e safrinha), na Fazenda de Ensino e Pesquisa da FEIS/UNESP, localizada no município de Selvíria-MS, nas coordenadas $20^{\circ} 22^{\prime}$ sul e $51^{\circ} 22^{\prime}$ oeste, com altitude de $335 \mathrm{~m}$. Segundo a classificação de Köppen, o clima é do tipo AW, com temperatura média anual de $25^{\circ} \mathrm{C}$, precipitação média anual de $1330 \mathrm{~mm}$ e umidade relativa média de $66 \%$ (HERNANDEZ et al., 1995). O solo é do tipo Latossolo Vermelho distrófico, típico argiloso, A moderado, hipodistrófico, álico, caulínico, férrico, compactado, muito profundo e moderadamente ácido ( $\mathrm{LVd}$ ) (EMBRAPA, 1999).

Para a realização dos experimentos, foram utilizadas 71 progênies de meios irmãos do composto Isanão VF-1, avaliadas em blocos ao acaso, com três repetições. As parcelas experimentais foram constituídas de duas linhas de cinco metros, contendo 36 plantas espaçadas entre si de $27,8 \mathrm{~cm}$. O espaçamento entre linhas foi de $0,45 \mathrm{~m}$, configurando uma população de 80.000 plantas ha ${ }^{-1}$, nas duas épocas avaliadas.

A semeadura foi realizada em plantio direto, sendo distribuído o dobro do número de sementes por cova, realizando-se o desbaste no estádio de cinco folhas desenvolvidas. Utilizou-se uma adubação de $300 \mathrm{~kg} \mathrm{ha}^{-1}$ da fórmula 8-28-16 na semeadura e duas adubações em cobertura, sendo aplicados $200 \mathrm{~kg} \mathrm{ha}^{-1}$ da fórmula 20-00-20 e 100 $\mathrm{kg} \mathrm{ha}^{-1}$ de uréia, respectivamente, nos estádios de quatro e sete folhas estabelecidas. As práticas culturais foram aquelas normalmente usadas em um cultivo de média/alta tecnologia e uniformes em todos os experimentos, a fim de minimizar a influência de fatores bióticos e abióticos que não faziam parte dos tratamentos (FANCELLI \& DOURADO-NETO, 2000).

Os caracteres avaliados foram: altura de plantas (AP - média de dez plantas da parcela); altura de espigas ( $\mathrm{AE}$ - média das mesmas dez plantas avaliadas para altura de plantas); tombamento (TOMB - \% de plantas acamadas mais \% de plantas quebradas); prolificidade (PRO) e; rendimento de grãos corrigido para $13 \%$ de umidade e estande ideal de 36 plantas por parcela (REND), por meio do coeficiente de regressão entre rendimento e estande observado, obtido pela análise de covariância entre os dois caracteres.

Após a realização das análises de variâncias individuais, foi verificada a homogeneidade das variâncias residuais pelo teste de F máximo, que considera as variâncias residuais homogêneas quando a relação entre os quadrados médios residuais não ultrapassa o valor 7 (GOMES, 2000). Constatada a homogeneidade das variâncias residuais, procedeu-se à análise de variância conjunta. O componente de variação da interação progênies x épocas de semeadura foi quantificado, considerando-se o efeito de genótipos aleatório e o de ambientes como fixo, conforme CRUZ et al. (2004). O quadrado médio da interação foi decomposto nas partes simples e complexa, utilizandose a expressão proposta por CRUZ \& CASTOLDI (1991). 
Foram obtidas as estimativas dos componentes da variância conjunta, sendo o estimador da variância genotípica entre famílias expresso por:

$\hat{\sigma}_{G}^{2}=\frac{Q M_{P}-Q M_{R}}{e r}$, em que: $Q M_{P}$ :quadrado médio das progênies; $Q M_{R}$ : quadrado médio do resíduo; r: repetição e; e: épocas de semeadura. A variância fenotípica

foi expressa pela seguinte equação: $\hat{\sigma}_{F}^{2}=\frac{Q M_{P}}{e r}$. A variância residual foi expressa por: $\hat{\sigma}_{r}^{2}=\frac{Q M_{R}}{e r}$. A variância da interação genótipo $\mathrm{x}$ ambiente foi determinado pela equação: $\hat{\sigma}_{G A}^{2}=\frac{Q M_{E x P}-Q M_{R}}{r} \cdot \frac{e-1}{e}$, sendo $Q M_{E x P}=$ quadrado médio da interação progênie x épocas de semeadura. A herdabilidade com base na média de famílias foi estimada pela expressão: $\hat{h}_{x}^{-2}=\frac{\hat{\sigma}_{G}^{2}}{\wedge^{2}}$. $\sigma_{F}$

O coeficiente de variação genético percentual $\left(C V_{g}\right)$ foi obtido por: $C V g=100 \sqrt{\frac{\sigma_{g}^{2}}{\bar{X}}} ;$ o coeficiente de variação residual percentual $\left(C V_{e}\right)$, por: $C V e=100 \sqrt{\frac{\sigma_{r}^{2}}{\bar{X}}}$ e o índice de variação pela equação: $\hat{I}_{v}=\frac{C V g}{C V e}$ (CRUZ \& CARNEIRO, 2003). As predições dos ganhos por seleção foram obtidas pelo índice proposto por MULAMBA \& MOCK (1978), tendo como pesos econômicos adotados: a) Desvio padrão genotípico (DPg); b) Coeficiente de variação genotípico (CVg); c) Índice de variação (Iv); d) Herdabilidade (h²) e; d) Pesos atribuídos por tentativas (PT) de magnitudes de 18, 16, 20, 20,50, respectivamente, para os caracteres AP, AE TOMB, PRO e REND, utilizando intensidade de seleção de $20 \%$. Esse índice se baseia em soma de ranks, ou seja, consiste em classificar os materiais genotípicos em relação a cada um dos caracteres, em ordem favorável ao melhoramento. Uma vez classificadas, as posições são somadas em ordem de cada material genético referente a cada caráter, resultando uma medida adicional adotada como índice de seleção. Os caracteres AP, AE e TOMB foram selecionados para decréscimo e os caracteres PRO e REND foram selecionados para acréscimo. As análises foram realizadas com o auxílio do aplicativo computacional GENES (CRUZ, 2001).

\section{RESULTADOS E DISCUSSÃO}

As análises de variância individuais em relação a AP, AE, TOMB, PRO e REND, nas duas épocas, indicaram que as progênies apresentaram variações significativas $(\mathrm{P}<0,01)$. Os coeficientes de variação dos caracteres oscilaram entre 6,97\% (altura de planta) a 20,54\% (rendimento de grãos). Esses valores são considerados satisfatórios, segundo a classificação proposta por SCAPIM et al. (1995), garantindo a validade das conclusões inferidas.

Uma vez verificada a homogeneidade das variâncias residuais pelo teste de F máximo, entre as duas épocas, cujos valores das relações foram 1,17, 1,52, 3,85, 1,18 e 5,37 em relação a AP, AE, TOMB, PRO e REND, respectivamente, realizou-se a análise de variância conjunta dos experimentos. Pelo teste F, foi possível verificar efeito significativo $(\mathrm{P}<0,0001)$ de progênies e épocas para todos os caracteres estudados. Esse resultado indica a existência de variabilidade genética suficiente entre as progênies a ser explorada em ciclos futuros de seleção e também indica que existe diferença entre as épocas avaliadas (Tabela 1). Na interação progênies x épocas, ocorreram diferenças significativas $(\mathrm{P}<0,01)$ para os caracteres AP, TOMB, PRO e REND, enquanto para AE houve diferença a 4,22 \% de probabilidade (Tabela 1).

A ocorrência de interação indica resposta diferencial dos genótipos às mudanças de ambiente e, na concepção de RAMALHO et al. (1993), a significância da interação genótipos por ambientes requer a identificação de cultivares com adaptação mais específica ou que sejam menos afetadas pela variação dos ambientes.

Quanto ao tipo de interação, houve predomínio do tipo simples, exceto para o caráter PRO, que revelou $86 \%$ de interação complexa (Tabela 2). 
Tabela 1 - Estimativas dos quadrados médios, das médias e dos coeficientes de variação experimental de cinco caracteres avaliados em 71 progênies de meios-irmãos do composto Isanão VF-1 de milho.

\begin{tabular}{|c|c|c|c|c|c|c|}
\hline \multirow{2}{*}{ FV } & \multirow{2}{*}{ GL } & \multicolumn{5}{|c|}{----------------------------------------------------Quadrados médios'-------------------------------------------------- } \\
\hline & & AP & $\mathrm{AE}$ & TOMB & PRO & REND \\
\hline Bloco & 2 & 1140,66 & 864,74 & 416,93 & 0,0035 & 0,1087 \\
\hline Progênies (P) & 70 & $787,4551^{* *}$ & $516,37^{* *}$ & $397,28^{* *}$ & $0,0506^{* *}$ & $0,7693^{* *}$ \\
\hline Época (E) & 1 & $168366,10^{* *}$ & $33789,75^{* *}$ & $455630,69^{* *}$ & $17,8126^{* *}$ & $313,4482^{* *}$ \\
\hline $\mathrm{P} \times \mathrm{E}$ & 70 & $218,2116^{* *}$ & $104,40^{*}$ & $376,96^{* *}$ & $0,0298^{* *}$ & $0,4551^{* *}$ \\
\hline Resíduo & 282 & 129,80 & 76,5952 & 75,53 & 0,0180 & 0,1450 \\
\hline Média & & 134,99 & 62,82 & 34,75 & 0,8643 & 1,90 \\
\hline CVe (\%) & & 8,44 & 13,93 & 25,01 & 15,52 & 20,04 \\
\hline
\end{tabular}

${ }^{1}$ AP: altura de planta em cm; AE: altura de inserção da primeira espiga em cm; TOMB: tombamento em porcentagem; PRO: prolificidade e REND: rendimento de grãos em kg parcela ${ }^{-1}{ }^{*},{ }^{* *} \mathrm{e}^{\mathrm{NS}}$ significativo a 1 e $5 \%$ de probabilidade e não significativo, respectivamente

Segundo CRUZ et al. (2004), a interação do tipo complexa indica a inconsistência da superioridade de genótipos com a variação ambiental, ou seja, haverá genótipos com desempenho superior em um ambiente mas não em outro, tornando mais difícil a seleção e/ou a recomendação destes. Como a maioria das características teve como predomínio a interação do tipo simples e, além disso, a existência de alta correlação genotípica entre rendimento de grãos e prolificidade $\left(r_{g}=0,82\right)$, pode-se selecionar as progênies superiores com base na média das duas épocas de semeaduras.

As estimativas da variância fenotípica $\left(\hat{\sigma}_{F}^{2}\right)$, genotípica $\left(\hat{\sigma}_{G}^{2}\right)$ e residual $\left(\hat{\sigma}_{r}^{2}\right)$, bem como da herdabilidade com base na média das progênies e $\left(\hat{h}_{\bar{x}}^{\bar{x}}\right)$ do coeficiente de variação genético $(\hat{\mathrm{CVg}})$ e do índice de

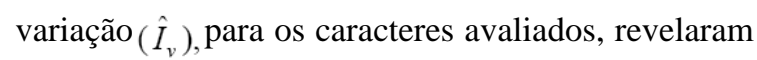
elevadas estimativas das variâncias genotípicas para as características AP, AE, TOMB e REND,

Tabela 2 - Estimativas das interações complexas para cinco caracteres avaliados em 71 progênies de meiosirmãos do composto Isanão VF-1 de milho (Safra e Safrinha).

\begin{tabular}{lc}
\hline Características & $\begin{array}{c}\text { Estimativas } \\
\text { percentuais das } \\
\text { interações complexas }\end{array}$ \\
\hline Altura de planta & 40,55 \\
Altura de inserção da primeira espiga & 34,94 \\
Tombamento & 5,37 \\
Prolificidade & 86,00 \\
Rendimento & 38,19 \\
\hline
\end{tabular}

acompanhadas de valores de herdabilidade com base na média de famílias, acima de $80 \%$, e índice de variação com magnitudes superiores a 0,80. Para PRO, a herdabilidade e índice de variação foi de 64,29\% e 0,55, respectivamente (Tabela 3). Faluba et al. (2010), avaliando o potencial genético da população de milho UFV7 para melhoramento no Estado de Minas Gerais, verificaram valores de herdabilidade e índice de variação inferiores a $50 \%$ e $0,65 \%$, respectivamente, para produtividade de grãos $\left(\mathrm{kg} \mathrm{ha}^{-1}\right)$, altura de planta, altura de espiga e prolificidade. Dessa maneira, os resultados obtidos no presente estudo refletem a possibilidade de identificação de progênies superiores para as características avaliadas, sobretudo quanto a rendimento de grãos.

Pelo índice de MULAMBA \& MOCK (1978), os ganhos proporcionais mais adequados para o conjunto de caracteres avaliados foi obtido pelo emprego de pesos econômicos atribuídos por tentativas (Tabela 4), corroborando com os trabalhos de SANTOS et al. (2007), FREITAS JÚNIOR et al. (2009) e AMARAL JÚNIOR et al. (2010). Os ganhos preditos foram de 1,41, 0,86, -13,03, 9,54 e 16,12\% para AP, AE, TOMB, PRO e REND, respectivamente (Tabela 4).

Para AP, a média da população original foi de 134,98 cm (Limite superior - LS: 154,58cm e Limite inferior - LI: $106,00 \mathrm{~cm}$ ), enquanto para população selecionada foi de $136,89 \mathrm{~cm}$ (LS: $151,42 \mathrm{~cm}$ e LI: $117,92 \mathrm{~cm}$ ), obtendo um ganho de seleção (GS) de 1,59cm (Figura 1A). Já para AE, a média da população original foi de $62,82 \mathrm{~cm}$ (LS: $85,08 \mathrm{~cm}$ e LI: $39,33 \mathrm{~cm}$ ), enquanto para população selecionada foi de $63,36 \mathrm{~cm}$ (LS: $75,58 \mathrm{~cm}$ 
Tabela 3 - Estimativas da variância fenotípica $\left(\hat{\sigma}_{F}^{2}\right.$ ), da variância genotípica ( $\hat{\sigma}_{G}^{2}$ ), da variância residual ( $\hat{\sigma}_{r}^{2}$ ), da variância da interação genótipo "versus" ambiente $\left(\hat{\sigma}_{G A}^{2}\right.$ ), da herdabilidade com base na média de famílias $\hat{h}_{\bar{x}}^{-}$), do coeficiente de variação genético $(\hat{C V g})$ e do índice de variação $\left(\hat{I}_{v}\right)$ para cinco caracteres avaliados em 71 progênies de meios-irmãos do composto Isanão VF-1 de milho.

\begin{tabular}{|c|c|c|c|c|c|c|c|}
\hline Características $^{1 /}$ & $\hat{\sigma}_{F}^{2}$ & $\hat{\sigma}_{G}^{2}$ & $\hat{\sigma}_{r}^{2}$ & $\hat{\sigma}_{G A}^{2}$ & $\hat{h}_{\bar{x}}^{2}$ & $\hat{C V g}$ & $\hat{I}_{v}$ \\
\hline AP & 131.24 & 109,61 & 21,63 & 14,73 & 83,52 & 7,75 & 0,92 \\
\hline $\mathrm{AE}$ & 86,06 & 73,30 & 12,76 & 4,63 & 85,17 & 13,63 & 0,98 \\
\hline TOMB & 66,21 & 53,62 & 12,59 & 50,24 & 80,99 & 21,07 & 0,84 \\
\hline PRO & 0,0084 & 0,0054 & 0,003 & 0,002 & 64,29 & 8,53 & 0,55 \\
\hline REND & 0,1281 & 0,1041 & 0,024 & 0,0517 & 81,26 & 16,99 & 0,85 \\
\hline
\end{tabular}

${ }^{1 /}$ AP: altura de planta em cm; AE: altura de inserção da primeira espiga em cm; TOMB: tombamento em porcentagem; PRO: prolificidade e REND: rendimento de grãos em kg parcela ${ }^{-1}$.

e LI: 48,42cm), obtendo GS de 0,46cm (Figura 1B). Esse resultado é considerado satisfatório para ambas as características em virtude das condições regionais e o fato de se tratarem de progênies de porte anão.

Em relação à TOMB, a média da população original foi de 34,74\% (LS: 46,54\% e LI: 9,99\%), enquanto para a população selecionada foi de $30,22 \%$ (LS: 43,74\% e LI: 14,88\%), obtendo GS de-3,67\% (Figura 1C). Apesar do LS da população selecionada ter sido considerado alto, ele é considerado como um outliers no boxplot, ou seja, ponto fora do intervalo interquatis $-\mathrm{Q}_{3}+1,5 *\left(\mathrm{Q}_{3}-\mathrm{Q}_{1}\right)$. O ponto fora do intervalo interquartil é proveniente da progênie 3. Entretanto, essa progênie obteve o maior rendimento das progênies avaliadas (2,79kg parcela-1) e, portanto, foi selecionada pelo índice multivariado MULAMBA \& MOCK (1978).

Para PRO, a média da população original foi de 0,86 (LS: 1,06 e LI: 0,63), enquanto para população selecionada foi de 0,95 (LS: 1,07 e LI: 0,83) obtendo GS de 0,0579 (Figura 1D). Em relação à REND, a média da população original foi de $1,89 \mathrm{~kg}_{\text {parcela }}{ }^{-1}$ (LS: $2,79 \mathrm{~kg}$ parcela $^{-1}$ e LI: $0,77 \mathrm{~kg}_{\text {parcela }}{ }^{-1}$ ), enquanto a população selecionada foi de 2,20 (LS: 2,79kg parcela $^{-1} \mathrm{e} \mathrm{LI}$ : 1,84kg parcela $^{-1}$ ) obtendo GS de 0,2519kg parcela ${ }^{-1}$ (Figura 1E).

\section{CONCLUSÃO}

Existe variabilidade genética suficiente entre as progênies para ser explorada em futuros ciclos de seleção. Em relação ao tipo de interação, houve predomínio do tipo simples para maioria dos caracteres avaliados, exceto para prolificidade.

O peso econômico atribuído por tentativa foi o mais eficiente para obtenção de ganhos pelo índice proposto por MULAMBA \& MOCK (1978).

Tabela 4 -. Estimativas de ganhos percentuais pelo índice de seleção proposto por Mulamb e Mock com diferentes pesos econômicos ${ }^{1 /}$ em cinco caracteres ${ }^{2 \prime}$, avaliados em 71 progênies de meios-irmãos do composto Isanão VF-1 de milho.

\begin{tabular}{|c|c|c|c|c|c|}
\hline \multirow{2}{*}{ Características $^{2}$} & \multicolumn{5}{|c|}{ 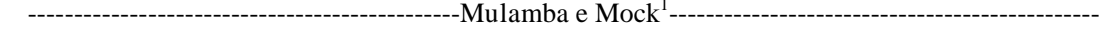 } \\
\hline & DPg & CVg & Iv & $h^{2}$ & PT \\
\hline AP & $-10,38$ & $-2,00$ & $-7,96$ & $-7,94$ & 1,41 \\
\hline $\mathrm{AE}$ & $-17,9$ & $-4,43$ & $-14,08$ & $-13,9$ & 0,86 \\
\hline TOMB & $-19,18$ & $-21,78$ & $-21,63$ & $-18,02$ & $-13,03$ \\
\hline PRO & $-3,30$ & 6,79 & 3,64 & 4,13 & 9,54 \\
\hline REND & $-16,93$ & 6,66 & $-6,54$ & $-4,66$ & 16,12 \\
\hline
\end{tabular}

${ }^{1}$ Pesos econômicos utilizados nos índices de seleção: DPg: desvio-padrão genotípico; CVg: coeficiente de variação genotípico; Iv: índice de variação (relação CVg/Cve); h $^{2}$ : herdabilidade; e PT: pesos atribuídos por tentativas (18, 16, 20, 20, 50). ${ }^{2}$ AP: altura de planta em cm; AE: altura de inserção da primeira espiga em cm; TOMB: tombamento em porcentagem; PRO: prolificidade e REND: rendimento de grãos em kg.parcela ${ }^{-1}$. 

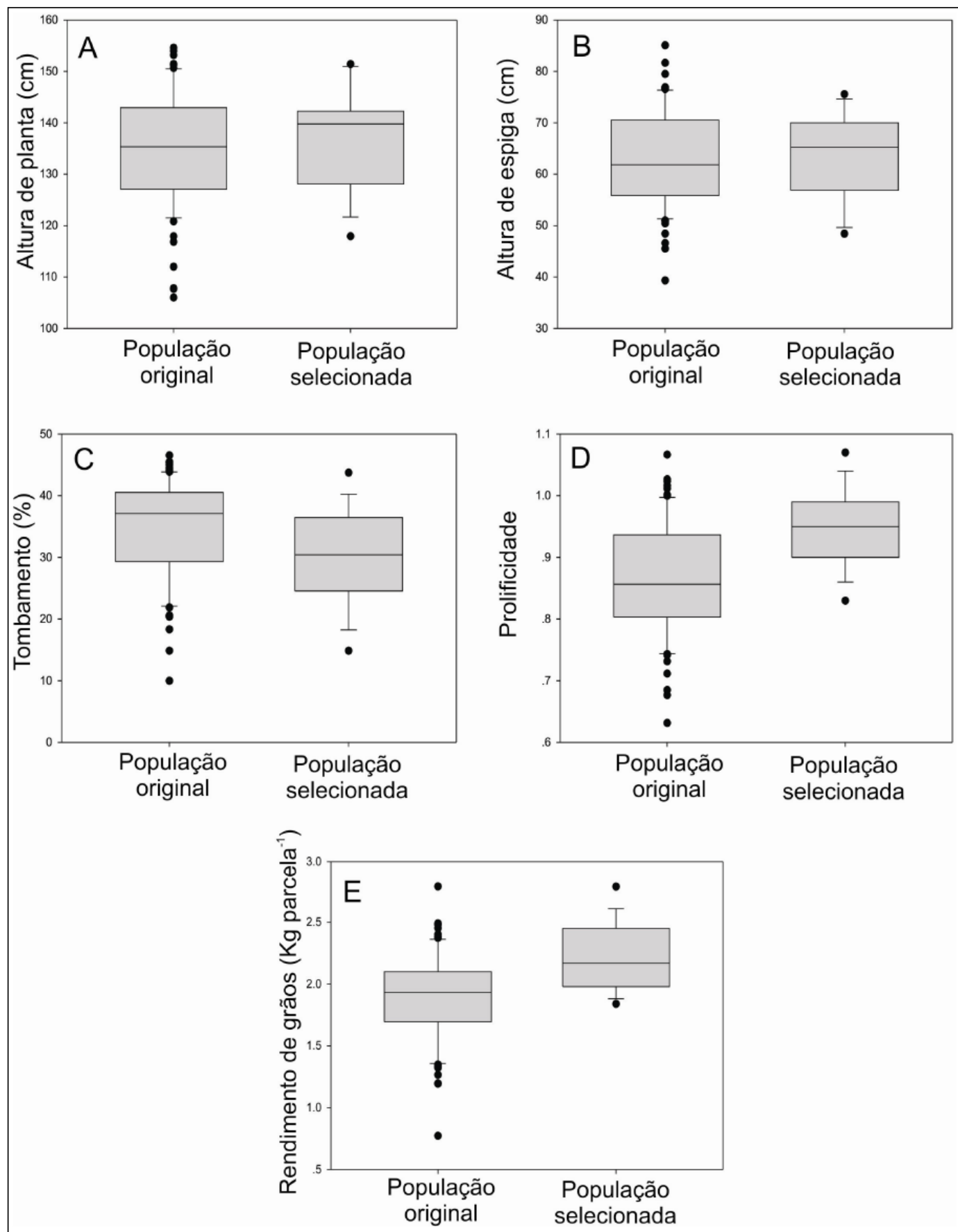

Figura 1 - Boxplot dos valores mínimos, máximos e mediana - 25, 50 e 75 - dos caracteres altura de planta, altura de espiga, tombamento, prolificidade e rendimento de grãos para população original e selecionada do composto Isanão VF-1 de milho, com base no índice de MULAMBA \& MOCK (1978).

\section{REFERÊNCIAS}

AGUIAR, R.A. et al. Análise económica de diferentes práticas culturais na cultura do milho (Zea mays L.). Pesquisa Agropecuária Tropical, v.38, p.241-248, 2008. Disponível em: <http:// http://www.revistas.ufg.br/index.php/pat/article/ view/3910/4229>. Acesso em: 14 jan. 2011.
AMARAL JÚNIOR, A.T. et al. Improvement of a popcorn population using selection indexes from a fourth cycle of recurrent selection program carried out in two different environments. Genetics and Molecular Research, v.9, p.340-347, 2010. Disponível em: <http://www.funpecrp.com.br/ gmr/year2010/vol9-1/pdf/gmr702.pdf>. Acesso em: $28 \mathrm{fev}$. 2011. doi: 10.4238/vol9-1gmr702.

Ciência Rural, v.41, n.6, jun, 2011. 
CANDIDO, L.S.; ANDRADE, J.A.C. Breeding potential of maize composite Isanão VF1 in small spacing in the second growing season. Crop Breeding and applied Biotechnology, v.8, p.56-64, 2008. Disponível em: <http://www.sbmp.org.br/ cbab/siscbab/uploads/bd6b9df0-1265-6fb7.pdf $>$. Acesso em: 28 fev. 2011

CARGNIN, A. et. al. Interação ente genótipos e ambientes e implicações em ganhos com seleção em trigo. Pesquisa Agropecuária Brasileira, v.41, p.987-993, 2006. Disponível em: <http://www.scielo.br/pdf/pab/v41n6/30865.pdf>. Acesso em: 28 fev. 2011. doi: 10.1590/S0100-204X2006000600014.

CRUZ, C.D.; CASTOLDI, F.L. Decomposição da interação genótipos x ambientes em partes simples e complexa. Revista Ceres, v.38, p.422-430, 1991. Disponível em: <http:// www.ceres.ufv.br/ceres/revistas/V38N219P04091.pdf>. Acesso em: 28 fev. 2011.

CRUZ, C.D. Programa GENES: versão windows; aplicativo computacional em genética e estatística. Viçosa: UFV, 2001. 648p.

CRUZ, C.D. et al. Modelos biométricos aplicados ao melhoramento genético. 3.ed. Viçosa: UFV, 2004. V.1, 480p.

EMPRESA BRASILEIRA DE PESQUISA AGROPECUÁRIA. Sistema brasileiro de classificação de solos. Rio de Janeiro: EMBRAPA-CNPS, 1999. 412p.

FALUBA, J.S. et al. Potencial genético da população de milho UFV7 para o melhoramento em Minas Gerais. Ciência Rural, v.40, p.1250-1256, 2010. Disponível em: <http:// submission.scielo.br/index.php/cr/article/view/20516/2850> Acesso em: 28 fev. 2011. doi: 10.1590/S010384782010000600002 .

FANCElli, L.A.; DOURAdo-Neto, D. Produção de milho. Guaíba: Agropecuária, 2000. 360p.
FREITAS JÚNIOR, S.P. et al. Genetic gains in popcorn by full-sib recurrent selection. Crop Breeding and Applied Biotechnology, v.9, p.1-7, 2009. Disponível em: <http:// www.sbmp.org.br/cbab/siscbab/uploads/c8129491-53d5e8f2.pdf>. Acesso em: 28 fev. 2011.

HERNANDEZ, F.B.T. et al. Software hidrisa e o balanço hídrico de Ilha Solteira. Ilha Solteira: UNESP/FEIS, 1995. 45p. (Série Irrigação, 1).

GARCIA, F.Q. Potencial do composto Flintisa anão de milho para melhoramento em condições de alta densidade populacional. 2005. 84f. Dissertação (Mestrado em Agronomia) - Curso de Pós-graduação em Agronomia, Universidade Estadual de São Paulo, SP.

GOMES, F.P. Curso de estatística experimental. Piracicaba: USP/ESALQ, 2000. 477p

MULAMBA, N.N.; MOCK, J.J. Improvement of yield potential of the Eto Blanco maize (Zea mays L.) population by breeding for plant traits. Egyptian Journal of Genetics and Cytology, n.7, p.40-51, 1978.

RAMALHO, M.A.P. et al. Genética quantitativa em plantas autógamas: aplicações ao melhoramento do feijoeiro. Goiânia: UFG, 1993. 271p.

SANTOS, F.S. et al. Predição de ganhos genéticos por índices de seleção na população de milho pipoca UNB-2U sob seleção recorrente. Bragantia, v.66, p.391-398, 2007. Disponível em: <http://www.scielo.br/pdf/brag/v66n3/a04v66n3.pdf>. Acesso em: 27 fev. 2011. doi: 10.1590/S000687052007000300004 .

SCAPIM, C.A. et al. Uma proposta de classificação dos coeficiente de variação para a cultura do milho. Pesquisa Agropecuária Brasileira, v.30, p.683-686, 1995. Disponível em: <http://www.infoteca.cnptia.embrapa.br/bitstream/AISEDE/19429/1/pab13_maio_95.pdf>. Acesso em: 28 fev. 2011. 